\title{
The use of adaptable automation: effects of extended skill lay-off and changes in system reliability
}

\author{
Juergen Sauer and Alain Chavaillaz \\ Department of Psychology, University of Fribourg, Fribourg, Switzerland
}

Corresponding author: Juergen Sauer, Department of Psychology, University of Fribourg, Rue de Faucigny 2, 1700 Fribourg, Switzerland; phone: +41-26-3007622; Fax: +41-26-3009712; email: juergen.sauer@unifr.ch

\begin{abstract}
This experiment aimed to examine how skill lay-off and system reliability would affect operator behaviour in a simulated work environment under wide-range and large-choice adaptable automation comprising six different levels. Twenty-four participants were tested twice during a 2-hr testing session, with the second session taking place 8 months after the first. In the middle of the second testing session, system reliability changed. The results showed that after the retention interval trust increased and self-confidence decreased. Complacency was unaffected by the lay-off period. Diagnostic speed slowed down after the retention interval but diagnostic accuracy was maintained. No difference between experimental conditions was found for automation management behaviour (i.e. level of automation chosen and frequency of switching between levels). There were few effects of system reliability. Overall, the findings showed that subjective measures were more sensitive to the impact of skill lay-off than objective behavioural measures.
\end{abstract}

Keywords: automation, reliability, skill lay-off, trust, complacency 


\section{Introduction}

The concept of adaptable automation has been considered a promising approach because it allows for a more flexible workload management by enabling the operator to choose freely the level of support offered by the automatic system (e.g. Parasuraman \& Wickens 2008). Such automation design permits operators to compensate for suboptimal working conditions, including task overload or underload, extended working hours, and environmental stressors (e.g. noise), which may all eventually result in increasing fatigue and an augmented risk of performance decrements (Hockey, 1997). The operator may select a higher level of automation because he or she wishes to be relieved of some tasks during the presence of some forms of suboptimal working conditions. For example, there is empirical evidence that automation may help operators maintain performance during loss of sleep (Reichenbach, Onnasch \& Manzey, 2011). A suboptimal working condition that has been given rather little attention in research until now is the issue of skill lay-off over an extended period of time. The non-use of skill may occur for two main reasons: some tasks are only carried out periodically (e.g. during start-up or shut-down procedures of process control systems) or a system is used regularly but only under high levels of automation with reduced operator involvement (e.g. operator manages a system in supervisory control). In both instances, this may result in loss of skill or deskilling (e.g. Wiener, 1988; Casner, Geven, Recker \& Schooler, 2014). Adaptable automation may provide support by offering high levels of automation which allows the operator to assign tasks that he or she finds difficult to complete to the automatic system.

In automation research, there are only a modest number of studies that have used non-static forms of automation such as adaptive or adaptable automation (e.g. Kidwell et al., 2012; Sauer, Kao \& Wastell, 2012). Whereas in adaptive automation, the machine decides which level of automation should be offered to the operator (e.g. on the basis of operator performance), in adaptable automation, the level of automation is selected by the human operator (e.g. Parasuraman \& Wickens, 2008). The design of adaptable automation is characterised by the number of levels the operator can choose from (small choice vs. large choice) and the range of levels of automation (LOA) available (narrow range vs. wide range). The number of levels available and the kind of support they offer have been described in various models of automation (e.g. Sheridan \& Verplank, 1978; Endsley, 1995). A recent review of automation models may be found in Vagia, Transeth and Fjerdingen (2016).

Wide-range and large-choice adaptable automation allows the operator to respond flexibly to different task demands. In the present study, the operator was able to make use of both elements of adaptable automation. Despite these obvious benefits of adaptable automation, there may also be a downside to it. While adaptable automation provides support to the operator in the form of high levels of automation, this may have negative effects on operator skills in the long term (deskilling due to non-practice) even though it helps maintain performance in the short term (e.g. the machine may compensate for poor operator performance). Since short-term benefits may only be obtained at the cost of long-term disadvantages, this may be considered a dilemma.

The issue of forgetting and skill loss has long been a topic in the field of ergonomics (e.g. Duncan, 1971). In addition to forgetting and skill loss associated with extended periods of non-practice, there are several other areas in which it is of concern, including impairments that are age-related (Czaja \& Sharit, 1993), fatigue-induced (Philip et al., 2003) or stressrelated (Hancock \& Vasmatzidis, 2003). These may occur in the form of temporary 
performance decrements (e.g. fatigue-related) or permanent decrements (e.g. age-related), which bears some resemblance to the distinction between competence and performance (Matthew, Davies, Westerman \& Stammers, 2000). The threat of skill loss can be combatted by several measures, such as by overlearning during training (e.g. Driskell, James, Willis \& Copper, 1992) and but also by using rest breaks (e.g. Tucker, 2003). The use of automation might also compensate for the negative effects of skill loss and help maintain performance. The problem of skill decay resulting from non-practice has been the subject of a number of studies. An important conclusion of such work was that performance on procedural tasks was particularly strongly impaired by extended periods of non-practice (e.g. Hagman \& Rose, 1983; Annett, 1979). Research modelling the complexity of human-machine systems in the laboratory found similar performance decrements after the lay-off period (e.g. Arthur et al., 1997; Sauer, Hockey \& Wastell, 2000). In this work, it also emerged that the magnitude of the performance decrement was influenced by type of task, with diagnosing faults in a process control environment being more strongly impaired than keeping the system in a stable state (e.g. Sauer, Hockey \& Wastell, 2000). Interestingly, the opposite pattern (i.e. system control performance was more strongly impaired than diagnostic performance) was observed in another study, which may be due to the availability of adaptable automation (Chavaillaz et al. (2016b). Both studies are highly relevant to the present work since they were similar in the retention interval and in the task environment employed. In particular, the more recent study by Chavaillaz et al. is to be considered the primary reference study since it also modelled adaptable automation. In the context of managing highly automated human-machine systems performance decrements occurring may be due to a complex pattern of effects involving variables such as trust, self-confidence, automation reliance, complacency, and system reliability. These variables are generally considered important in automation design and are also included in pertinent models (Wickens et al., 2004).

Trust may be considered being the extent to which the operator believes that the technical system will help him or her achieve task-related goals during uncertain operational conditions (Lee \& See, 2004). Trust towards machines may involve explicit and implicit processes (Merrit, Heimbaugh, LaChapell \& Lee, 2013). A recent review on trust in automation demonstrated that trust levels may be influenced by a wide range of factors that can be summarised into three major categories: dispositional trust (e.g. personality), situational trust (e.g. self-confidence) and learnt trust (e.g. past experience with system; Hoff \& Bashir, 2015). The present study examined a factor from the third category. It was expected that trust as an attitude towards the reliability of the automatic system would be influenced by the actual reliability level of the system. Operators may sometimes face difficulties when calibrating their trust to the actual level of system reliability (e.g. Wiegmann et al., 2001). The level of trust has important implication for operator behaviour in that automation may be over- or underestimated (misuse or disuse; Parasuraman \& Riley, 1997). Recent work has also shown that trust levels can be increased by indicating to the operator the probability of an alarm being correct (i.e. likelihood alarm system; Wiczorek \& Manzey, 2014). Surrounding the issue of trust calibration, it may be of particular interest how extended lay-off periods affect trust ratings but also behavioural manifestations of trust. Such behavioural manifestations include reliance on automation (e.g. LOA chosen by operator) and complacency (e.g. insufficient system monitoring). There is little research that has addressed this issue although long periods of skill lay-off are not uncommon in industrial settings. To our knowledge there is only one study that examined the effects of lay-off period on trust (Chavaillaz et al., 2016b). It showed stable patterns of trust ratings over an 8-month lay-off period.

While trust is considered an important influencing factor of automation use, operator selfconfidence may also moderate the relationship between trust and automation use. For 
example, if trust in automation exceeds the self-confidence of the operator in his or her ability to manage the system manually, operators would rely on automation rather than manual system control (Lee \& Moray, 1994). Conversely, operators would opt for manual system control if their self-confidence in being able to manage the system manually exceeded their trust in automation. First evidence from a study measuring operator self-confidence after an extended lay-off period suggests a decrease in ratings at the second testing session (Chavaillaz et al., 2016b).

Use of automation is one of the primary behavioural manifestations of trust (e.g. Lee \& See, 2004). This has sometimes also been referred to as reliance (e.g. Dzindolet, Peterson, Pomranky, Pierce \& Beck, 2003) or dependence (e.g. Wickens, Clegg, Vieane \& Sebok, 2015). Opting for high level of automation would clearly be a strategy for operator to relieve themselves of high workload and to assign those tasks to the machine which they find difficult to complete (e.g. because they forgot how to do them after the retention interval). Due to the general paucity of research on (wide-range) adaptable automation, there is even less work on the specific issue of skill retention. There is, to our knowledge, only one study that examined this question. The results of this study suggest that operator reliance on automation was high and very stable over the extended lay-off period (Chavaillaz et al., 2016b). This also applied to the frequency with which automation levels were changed.

Being defined as an insufficient monitoring of an automatic system that has negative consequences on operator performance (Parasuraman \& Manzey, 2010), complacency has emerged in a number of studies, in which automatic support system had failed (e.g. Bahner et al., 2008). Little is known about how complacency is affected by long periods of non-practice of skills. The only other study examining skill lay-off under adaptable automation failed to take a measure of complacency (Chavaillaz et al., 2016b). There is a study (not using adaptable automation) that also examined a measure related to complacency (i.e. information sampling behaviour) before and after a lay-off period (Sauer, Hockey \& Wastell, 2000). The findings suggest that information sampling behaviour significantly increased after the retention interval implying that there was no evidence for complacency being on the increase.

Changes in system reliability may have effects on several parameters including trust, performance, and confidence (Wiegmann et al., 2001; De Visser \& Parasuraman, 2011). Furthermore, it may be of relevance whether the reaction will depend on the direction this change will take (i.e. increase vs. decrease). For example, it may make a difference whether there was an increase or a decrease in reliability experienced by the operator (e.g. prior to the current reliability level of $70 \%$ the operator either experienced $50 \%$ or $90 \%$ reliability). More recent work has also shown that prior operator experience with diagnostic failures of the automation affects trust ratings and automation verification behaviour (Manzey, Reichenbach and Onnasch, 2012). There is hardly any research on the impact of the direction of change in automation reliability, with only one study examining such a question (Wiegmann et al., 2001). It showed that it made little difference whether a change in reliability to $80 \%$ occurred from a baseline of $60 \%$ or $100 \%$, except for trust which was lost more quickly than it was regained. The issue raised may also be related to the question of whether the adjustment in reliability levels involves a qualitative change. The findings of two meta-analyses have suggested that there may be a critical point which, if crossed over, will lead to more substantial changes to performance and state of the operator (Onnasch et al., 2014; Wickens \& Dixon, 2007). A reliability level of $70 \%$ has been identified as a critical 'cross-over point' because below that point automation seems to provide little benefit. 
The goal of this study was twofold. First, it aimed to examine the effects of a prolonged layoff period on operator behaviour (e.g. performance, complacency, reliance on automation) as well as on subjective operator responses (e.g. workload and trust ratings) in the operational context of adaptable automation. Second, it aimed to examine the effects of changes in reliability after the lay-off period with a view to comparing increases and decreases of the same magnitude.

During training, operators were taught how to manage a complex process control environment, which was supported by adaptable automation. After training, operators took part in two testing sessions (the first one about one week after training and the second one about 8 months later) which comprised a series of fault scenarios. In the first testing session, operators either worked with a high or low-reliability system. In the second testing session, they faced exactly the same fault scenarios as in the first one. In the first half of the second testing session, operators used exactly the same reliability level (i.e. either high or low). In the second half, both experimental groups were given a system with medium reliability. This represented a decrease in reliability for the high-reliability group and an increase for the lowreliability group.

The impact of reliability changes has been examined previously (Wiegmann et al., 2001; Chavaillaz et al., 2016b) but none of that work has investigated it after an extend lay-off period. An increase in reliability may occur if a system is replaced by another one with a higher reliability level or if an automatic software update is carried out. Conversely, a reduction in reliability may occur if the operational conditions change such that system reliability is affected (e.g. extreme cold) or due to the usual wear and tear of system components. The change in reliability is similar to the experimental manipulation used by Wiegmann et al. (2001) but the present study employs a more complex task environment (in which operators can also independently verify the decision of the automation for correctness) and uses a broader set of dependent variables. This allows us to determine whether similar findings are to be expected in a different type of task environment and after a lay-off period.

The present work also builds on a previous study (Chavaillaz et al., 2016b) with regard to the set-up of the simulation environment but differs in a number of features. The simulation environment employed now models six rather than five levels of automation, a measure of complacency is taken, a change in reliability occurs after the retention interval, and an additional measurement of trust is taken immediately prior to the beginning of the testing session. The additional measure of trust is important to determine how well trust ratings are maintained over the long lay-off period during which no interaction with the technical system takes place.

In order to examine the multiple effects associated with adaptable automation, a PC-based simulation modelling a process control environment was used comprising multiple tasks to which different priorities are attached (e.g. Hockey et al., 1998; Lorenz et al., 2002; Manzey et al., 2008). This allowed us to measure operator performance on primary tasks as well as on secondary tasks. In addition to performance measures, subjective ratings of trust, selfconfidence, and workload were taken together with measures of complacency, automation bias, and automation management behaviour. The adaptable support system represents a central element of the process control simulation. The present version models six LOA rather than five, which is a significant enhancement over previous versions of the simulation (e.g. Chavaillaz et al., 2016a). The additional level, LOA6 in the framework of Sheridan and Verplank (1978), allows for a largely autonomous system operation, not requiring any operator input if a system repair needs to be initiated. This additional LOA permits us to 
observe operator behaviour and subjective responses under conditions where no operator intervention is required.

A part of the data set from the first testing session was also used in a separate publication, addressing a different research question (Chavaillaz \& Sauer, 2016). It examined the effects of mismatches and matches in system reliability experienced during training and testing while the present experiment focussed on the effect of changes in reliability after an extended layoff period. In addition to analysing the effects of the experimental manipulations, we also carried out a correlational analysis. This would allow us to examine the strengths of associations between variables that are of interest from a theoretical perspective (e.g. relationship between frequency of LOA changes and performance).

While the research literature has shown that there are a number of studies on the effects of lay-off, there is very little work that specifically addressed this issue in the context of (adaptable) automation. For example, it is unclear whether adaptable automation will provide benefits to performance (e.g. automation will compensate for decrements of operator performance) or will have the opposite effect (e.g. automation management will be impaired after the long retention interval). Therefore, the present work is, to some extent, explorative in its nature. Nevertheless some hypotheses were put forward on the basis of the limited research available. It was hypothesised that trust levels would remain stable but self-confidence would decrease after the retention interval. We expected that operators may compensate skill decrements after the retention interval by choosing higher LOA. With regard to the effects of changes in system reliability, we expected trust ratings to reflect more strongly these changes than other measures.

\section{Method}

\subsection{Participants}

Twenty-four students ( 1 female), aged 21 to 38 yrs $(M=24.5, S D=4.1)$, took part in the study. In the first testing session, 40 participants were tested (Chavaillaz and Sauer, 2016), that is, $60 \%$ of participants from the original sample were available a second testing session. There were no differences between the drop-outs and the students participating for a second time with regard to their performance on the primary tasks. All participants had a background in science or engineering to ensure that their competencies bear some similarity to real process control operators. Participants received a payment of CHF 60 (€ 55) for their participation.

\subsection{Experimental design}

A $4 \times 2$ mixed design was used in this study. The first factor testing phase was a repeated measures factor and had four levels. The second factor was system reliability with two levels: high (100\% reliable) and low (60\% reliable). Both factors contained several subfactors of which the effects were tested by means of planned comparisons (see also description of data analysis below). The main factor testing phase consisted of two subfactors: lay-off period and time-on-task. Lay-off period (phase 1 vs. phase 3 ) examined the effects of non-use of system. The subfactor time-on-task referred to the early or late phase in each testing session (i.e. phase 1 vs. phase 2). The interaction of both main factors also comprised the subfactor reliability change in which a change in reliability occurred between phases 3 and 4 (representing a decrease for half the participants and an increase for the other half), with both groups working with a level of system reliability of $80 \%$ in phase 4 . For one of the dependent variables (trust), a $5 \times 2$ design was used because there was an additional point of measurement just prior to the beginning of the second testing session (see also 3.1.) 


\subsection{Simulation environment}

The process control environment AutoCAMS (Automated Cabin Air Management System) simulates a life-support system in a space cabin. Several research teams have contributed to the development of the simulation over a considerable number of years (e.g. Hockey et al., 1998; Lorenz et al., 2002; Manzey et al., 2008; Sauer, Kao \& Wastell, 2012). In the present study, an enhanced version of the simulation was used, modelling six different LOAs (corresponding to LOA1-6 in the classification system of Sheridan and Verplank, 1978).

AutoCAMS comprises a highly automated system that controls the air quality in a spacecraft. System management requires maintaining five parameters $\left(\mathrm{O}_{2}\right.$, pressure, $\mathrm{CO}_{2}$, temperature, and humidity) within a predefined target range. The interface is depicted in Figure 1. On the top left, the space cabin is shown, with readings of the $\mathrm{O}_{2} / \mathrm{N}_{2}$ supply and technical symbols signalling the working of subsystems. On the bottom left, the interface shows a history display indicating the development of the five key parameters. On the top right, several displays and controls are depicted (i.e. target levels of flow rates, system clock, failure indicator, 'transmission control' icon, current repair status, manual controllers, $\mathrm{N}_{2}$ tank level recording facility, repair facility, and control panel for selecting six LOA). Finally, on the bottom right the interface of the support system AFIRA (Automated Fault Identification and Recovery Agent) is shown.

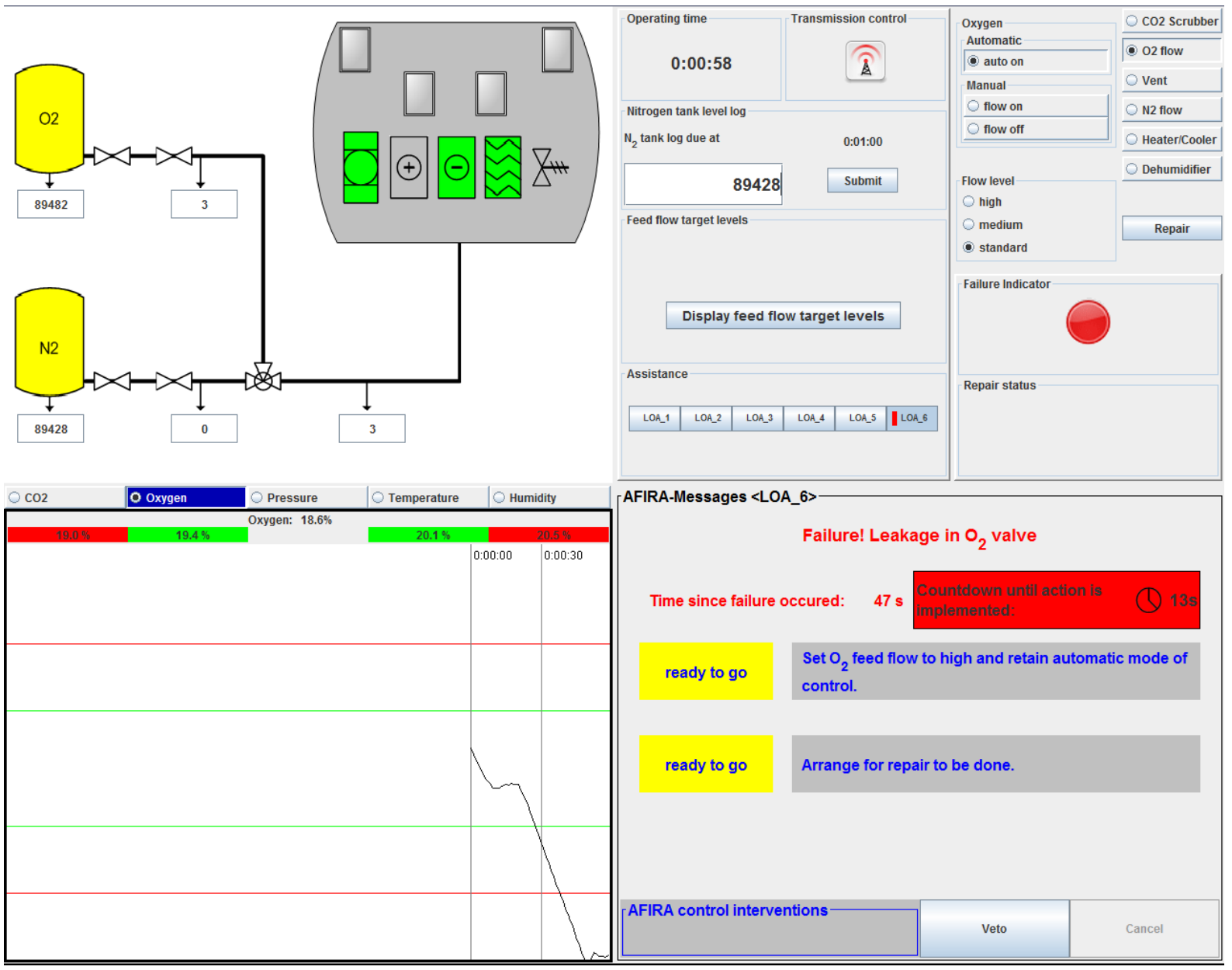

Figure 1. Main interface of the simulation AutoCAMS (Automated Cabin Air Management System). 
The adaptable support system AFIRA provided six LOA, which corresponded to the levels 16 described in the classification system of Sheridan and Verplank (1978). (a) LOA1: there was no support provided, with both fault diagnosis and system stabilisation having to be completed manually. (b) LOA2: an alarm informed the operator of the presence of a system fault but fault diagnosis and system stabilisation had to be carried out manually. (c) LOA3: in addition to the alarm, the system identified the system fault but again the operator needed to carry out the fault diagnosis without AFIRA guidance as well as to complete the system stabilisation procedure. (d) LOA4: a fault diagnosis and a course of action were proposed by AFIRA to stabilise the system fault but both had to be implemented by the operator. (e) LOA5: the system identified the system fault and executed the system stabilisation procedure if authorised by the operator. (f) LOA6: the system identified the fault and suggested a system stabilisation procedure, with both being executed within $60 \mathrm{~s}$ unless the operator exercised their right of veto. According to operational requirements, the operator was able switch between all six LOA available.

During AutoCAMS management, four tasks had to be completed by the participant. Being defined as primary tasks, the participant had (a) to diagnose and repair any occurring system fault and (b) to stabilise any disturbed system state by using manual system control if necessary. As secondary tasks, participants were asked (a) to log the current level of the $\mathrm{N}_{2}$ tank at 1-min intervals (prospective memory task) and (b) to click as quickly as possible on an alert (probe detection task). The alert was issued at irregular intervals averaging two alerts per minute.

\subsection{System reliability}

The level of system reliability was determined by the percentage of correct diagnoses made by AFIRA during the testing session. For participants in the high-reliability condition, AFIRA always offered a correct diagnosis (i.e. 100\% reliability). In the low-reliability condition, the diagnosis of the fault state was correct in 6 out of 10 cases (i.e. $60 \%$ reliability). It is important to note that the wrong diagnosis offered by AFIRA showed a pattern of symptoms similar to the actual system fault (e.g. a leak in the $\mathrm{N}_{2}$ valve was misdiagnosed as a block in the $\mathrm{N}_{2}$ valve). This was to ensure that the incorrect diagnosis was plausible to the participant to increase the probability of a misdiagnosis by the participant.

\subsection{Measures}

Trust in automation was measured by the Checklist of Trust between People and Automation (CTPA; Jian et al., 2000), comprising 12 items. Each item was rated on a 7-point Likert scale (e.g. "I can trust the system": not at all - totally agree).

To measure participant's self-confidence, two questions were taken from Lee and Moray's (1994) questionnaire on trust and self-confidence and slightly modified: "How confident were you in your fault diagnosis (very little - a great deal)?", "How confident were you in your manual control of the system parameters (very little - a great deal)?" Participants rated each question on a 10-point Likert scale.

The NASA-TLX (Hart \& Staveland, 1988) was used to measure participants' subjective workload. It consisted of 6 items representing different facets of workload (mental demands, physical demands, temporal demands, performance, frustration, and effort).

A measure of information sampling behaviour was taken to determine complacency towards automation. It was measured as a percentage by relating the number of diagnostic checks that 
were actually carried out by the participant to the number of checks they were prescribed by the fault diagnosis manual.

Automation management was measured by three indicators: (a) average LOA was an indicator of how strongly participants relied on automation ranging from 1 to 6; (b) frequency of LOA changes was an indicator for the variability of LOA choice; (c) manual control activity referred to the frequency of adopting manual control using one of the five manual controllers.

Performance was measured by five dependent variables. Performance on the primary task fault diagnosis and repair was measured by (a) the percentage of incorrectly diagnosed faults (fault identification accuracy) and (b) the time participants needed to initiate the correct repair (fault identification time). The participant's ability to maintain a stable system was assessed by (c) the percentage of time that a system parameter had moved outside its target state (deviations from stable system state). For prospective memory performance as a secondary task measure, we measured (d) the frequency with which participants failed to make tank level recordings on time, that is, outside a time window of $15 \mathrm{~s}$ before and after the moment when the recording was required (percentage of omissions). Finally, we took a measure of (e) the time needed to respond to the alert indicating that the connection between the ground station and the space shuttle was disrupted (alarm reaction time), representing a probe detection task.

\subsection{Procedure}

Participants were instructed that the purpose of the study was to examine operator behaviour in complex technical systems. Furthermore, they were informed that the study consisted of a training session and two testing sessions, with the first testing session taking place one week after training and the second one about eight months later.

\subsubsection{Training}

Participants were trained on AutoCAMS for about 3 hrs (including a 15 min break). They were given first a basic understanding of how AutoCAMS worked (e.g. they learnt to complete the four tasks comprising fault repair, system stabilisation, probe detection, and regular data logging. Then, participants were taught how to carry out a fault diagnosis without assistance from the automatic support system. This was followed by an introduction to the different levels of automatic support, ranging from LOA2 to LOA6). After participants had become familiar with the different automation levels, they were introduced to different fault states, allowing them to practise notably their skills in fault diagnosis and system stabilisation.

\subsubsection{Testing}

Two 2-hr testing sessions took place (including 2 x 40 min blocks, plus some extra time for instructions and questionnaire completion), the first one week after training and the second about 8 months later. Each testing session was divided into two phases (lasting about 40 min each), containing five faults each. The faults presented in each testing session were identical. Half of the participants were assigned to the high-reliability condition and worked with a fully reliable support system until $\mathrm{P} 4$. The other half was given a low-reliability system $(60 \%$ reliability). In this condition, two out of five system faults were misdiagnosed by the support system in each phase. The same reliability levels were also used in the first phase of the second testing session (i.e. P3) whereas in the second phase (i.e. P4) both reliability groups experienced a reliability level of $80 \%$.

Prior to the beginning of each testing session, participants were reminded of the four tasks to be completed and that they could change the level of automation of AFIRA at any time. After 
each phase, participants were asked to complete the questionnaires to measure trust, selfconfidence, and workload.

\subsection{Data analysis}

A mixed two-factorial analysis of variance (ANOVA) was computed to determine the influence of testing phase (4 levels) and system reliability (2 levels). For one measure (trust), a 5 x 2 ANOVA was conducted (see also 2.2. and 3.1.). If the effects were significant, planned comparisons were carried out in order to address research questions with regard to lay-off period and reliability changes. This included a comparison between P1 and P3 to test for an effect of retention interval, and the comparisons P1 vs P2 to test for time-on-task effects within a testing session.

The comparison P3 vs. P4 is equally important but more difficult to interpret for methodological reasons. In the case of changes from P3 to P4, its effects of time-on-task are confounded with a change in reliability. However, if both reliability groups move into the same direction, we could conclude that this was due to continuous practice during the second testing session. If the data for the two reliability groups show a different trend, we could conclude that this was due to the influence of changes in system reliability.

Degrees of freedom were adjusted according to Huynh-Feldt corrections. The level of significance for multiple comparisons was adjusted according to Bonferroni correction if necessary.

In addition, we carried out a correlational analysis to gain a deeper understanding of the relationships between the different variables. A correlation matrix was constructed, which included all data from the second testing session. If a variable was measured several times during the session (e.g. fault identification time), the arithmetic mean was entered into the analysis.

\section{Results}

\subsection{Subjective measures}

Trust. For the trust ratings, the ANOVA computed was a $5 \times 2$ model, due to the additional measurement (P3prior) being taken prior to the beginning of the second testing session. This allowed us to examine the level of trust during the lay-off period before the experience of the second testing session had taken an effect on the rating (planned comparison: P2 vs. P3prior). The data are presented in figure 2 . The analysis revealed a main effect of testing phase $(\mathrm{F}=$ 13.6; $\mathrm{df}=3.19,70.12 ; \mathrm{p}<.001 ; \eta^{2}$ partial $\left.=.38\right)$. A planned comparison showed a significant increase in ratings from the first to the second session $(\mathrm{F}=13.45 ; \mathrm{df}=1,22 ; \mathrm{p}<.001)$.

Further planned comparison between the different phases revealed a significant increase in ratings $\mathrm{P} 2$ and $\mathrm{P} 3$ prior $(\mathrm{F}=19.94 ; \mathrm{df}=1,22 ; \mathrm{p}<.001)$. There was no effect of reliability $(\mathrm{F}=$ $\left.3.28 ; \mathrm{df}=1,22 ; \mathrm{p}=.083 ; \eta_{\text {partial }}^{2}=.12\right)$. The interaction between testing phase and reliability was not significant $\left(\mathrm{F}=1.23 ; \mathrm{df}=3.19,70.12 ; \mathrm{p}=.304, \eta_{\text {partial }}^{2}=.05\right)$. 


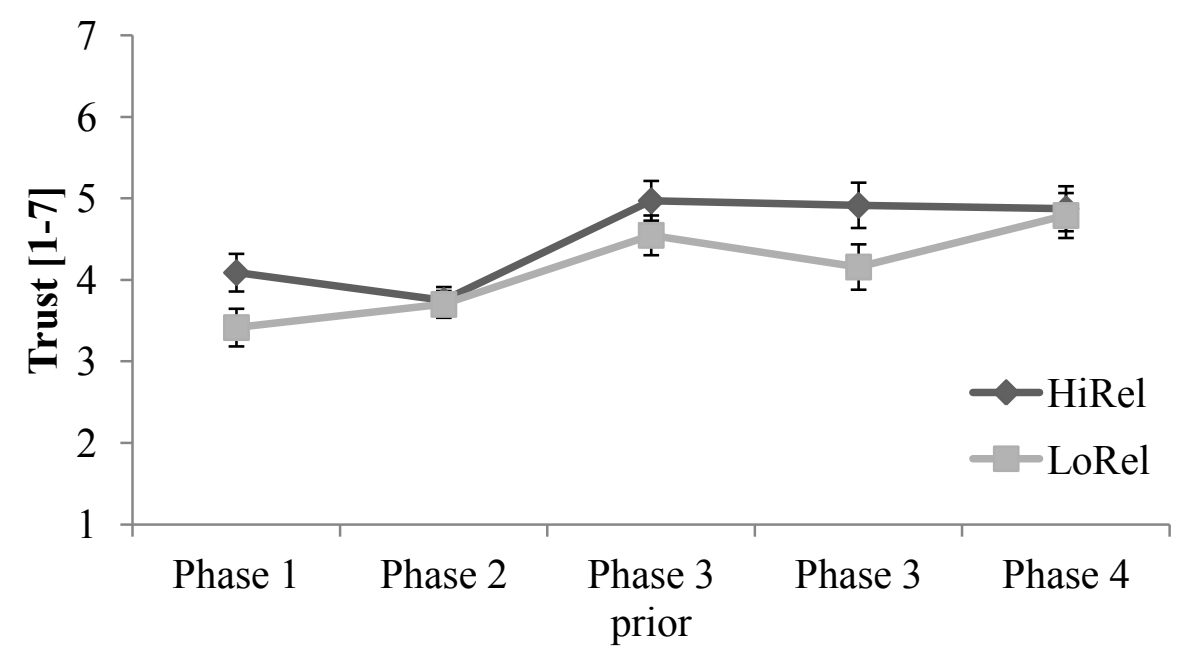

Session 1

Session 2

Figure 2: Mean ratings of trust (and standard errors) as a function of testing phase and reliability (HiRel: high reliability, LoRel: low reliability)

Self-confidence. Ratings of self-confidence were found to decrease after the retention interval (i.e. from P1 to P3) but recovered again in P4 (see figure 3). The main effect of testing phase was significant $\left(\mathrm{F}=7.21 ; \mathrm{df}=2.04,44.8 ; \mathrm{p}=.002 ; \eta^{2}\right.$ partial $\left.=.247\right)$. Planned comparisons revealed that the changes from $\mathrm{P} 1$ to $\mathrm{P} 3(\mathrm{~F}=4.50 ; \mathrm{df}=1,22 ; \mathrm{p}=.045)$ and from $\mathrm{P} 3$ to $\mathrm{P} 4(\mathrm{~F}=$ $15.86 ; \mathrm{df}=1,22 ; \mathrm{p}<.001)$ were significant. Analysis of variance also showed a significant interaction between testing phase and reliability $\left(\mathrm{F}=4.46 ; \mathrm{df}=2.04,44.8 ; \mathrm{p}=.016 ; \eta_{\text {partial }}^{2}=\right.$ .169). This was because the differences in self-confidence between the two reliability groups (HiRel had more confidence than LoRel) observed before the retention interval had disappeared after it (P1-P3: $\mathrm{F}=6.62 ; \mathrm{df}=1,22 ; \mathrm{p}=.017$. No main effect of reliability was found $\left(\mathrm{F}=2.15 ; \mathrm{df}=1,22 ; \mathrm{p}>.1 ; \eta_{\text {partial }}^{2}=.089\right)$.

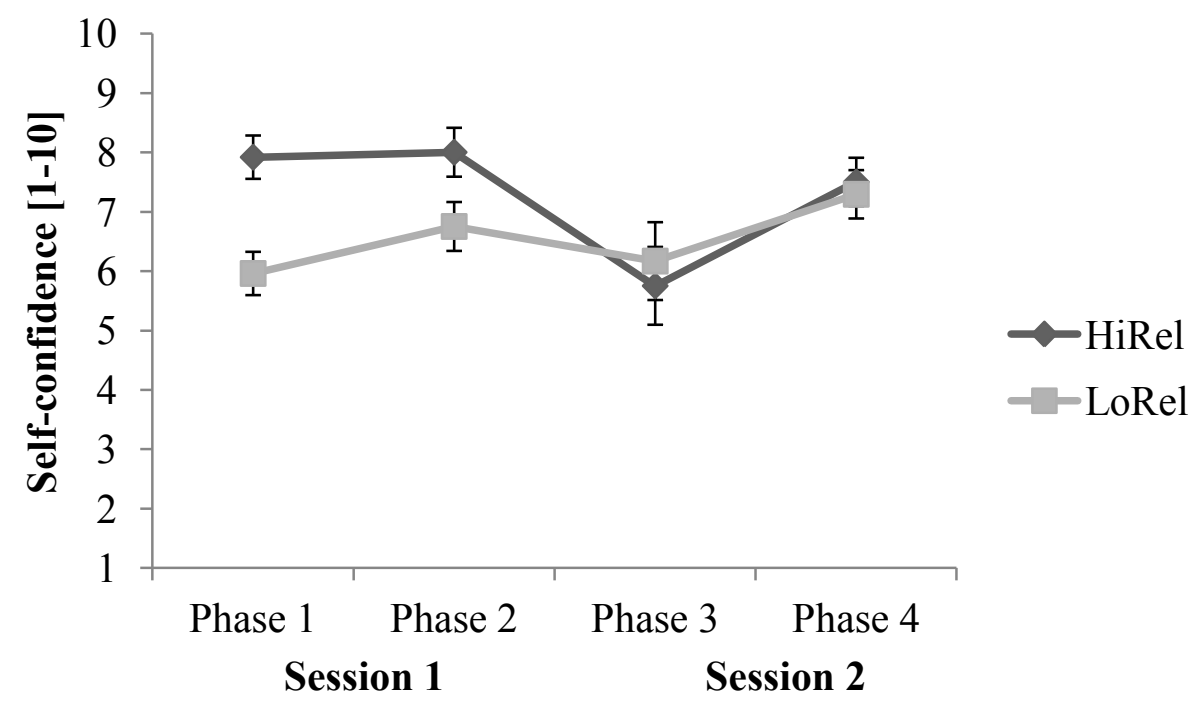

Figure 3: Mean ratings of self-confidence (and standard errors) as a function of testing phase and reliability (HiRel: high reliability, LoRel: low reliability) 
Perceived workload. The workload ratings over the four phases are presented in see figure 4. There was an increase after the retention interval, and in the second testing session ratings fell in the second half, with the pattern described being found to be statistically significant $(\mathrm{F}=$ $4.37 ; \mathrm{df}=2.49,54.9 ; \mathrm{p}=.007 ; \eta^{2}$ partial $\left.=.166\right)$. This was confirmed by planned comparisons (P1 vs. $\mathrm{P} 3: \mathrm{F}=4.57 ; \mathrm{df}=1,22 ; \mathrm{p}=.044 ; \mathrm{P} 1$ vs. $\mathrm{P} 2: \mathrm{F}=2.95 ; \mathrm{df}=1,22 ; \mathrm{p}=.100 ; \mathrm{P} 3$ vs. P4: $\mathrm{F}=6.47 ; \mathrm{df}=1,22 ; \mathrm{p}=.019)$. The analysis of variance revealed a marginally significant effect of reliability, with the HiRel-group experiencing lower workload than the LoRel-group $\left(\mathrm{F}=4.21 ; \mathrm{df}=1,22 ; \mathrm{p}=.052 ; \eta_{\text {partial }}^{2}=.160\right)$. There was no significant interaction $(\mathrm{F}=.37$; $\left.\mathrm{df}=2.49,54.9 ; \mathrm{p}=.732 ; \eta_{\text {partial }}^{2}=.017\right)$.

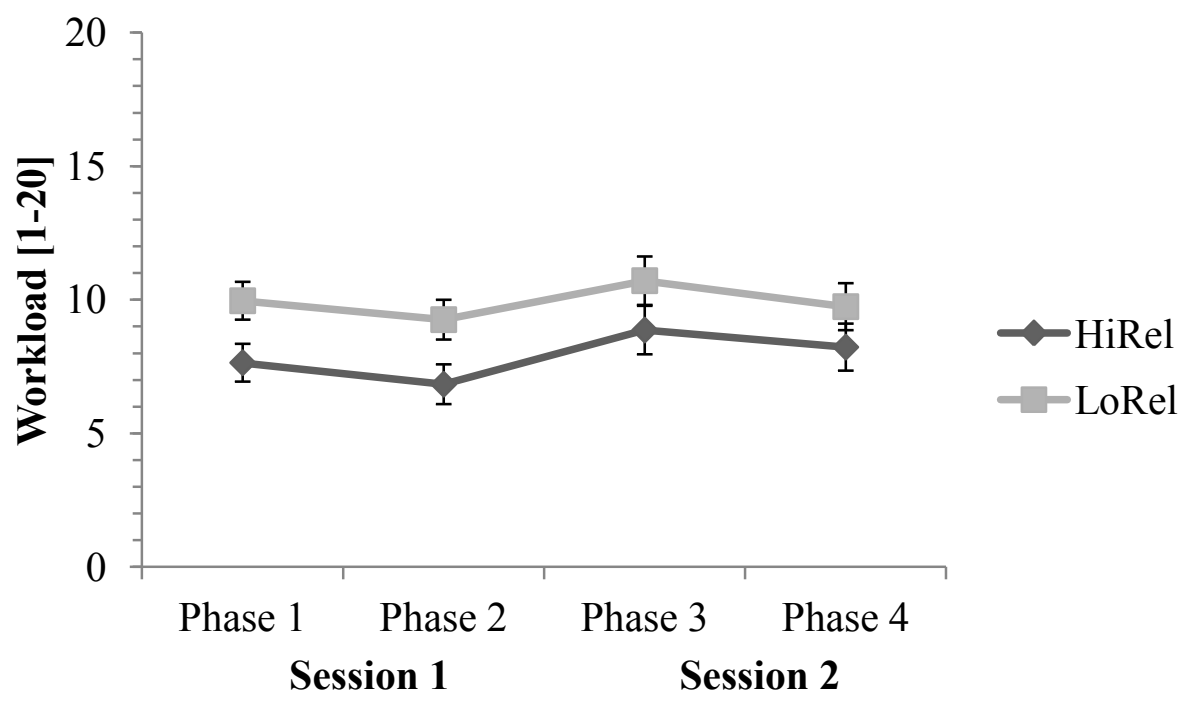

Figure 4: Mean ratings of workload (and standard errors) as a function of testing phase and reliability (HiRel: high reliability, LoRel: low reliability)

\subsection{Automation management}

Average LOA selection. The data for mean LOA selected are presented in table 1. Visual inspection of the data shows little difference between experimental conditions. This was confirmed by analysis of variance, which found no significant effects for testing phase $(\mathrm{F}=$ $\left.1.02, \mathrm{df}=1.5 ; 32.2 ; \mathrm{p}=.389 ; \eta_{\text {partial }}^{2}=.044\right)$, reliability $\left(\mathrm{F}=.06 ; \mathrm{df}=1,22 ; \mathrm{p}=.802 ; \eta_{\text {partial }}^{2}=\right.$ $.003)$, or the interaction between the two factors $\left(\mathrm{F}=.03 ; \mathrm{df}=1.5,32.2 ; \mathrm{p}=.939 ; \eta_{\text {partial }}^{2}=\right.$ $.001)$. At a descriptive level, the data showed that participants tended to choose automation levels in the upper half rather than towards the lower end (about level 4 out of 6).

Frequency of LOA change. The findings for LOA changes were similar to the above measure (see table 1). Again, the scores showed a remarkable stability across conditions. This was confirmed by analysis of variance, with no significant effects being found: phase $(\mathrm{F}=2.29$, $\mathrm{df}$ $\left.=3,66, \mathrm{p}=.086 ; \eta_{\text {partial }}^{2}=.094\right)$, reliability $\left(\mathrm{F}=.357 ; \mathrm{df}=1,66 ; \mathrm{p}=.557 ; \eta_{\text {partial }}^{2}=.016\right)$, and interaction $\left(\mathrm{F}=2.11 ; \mathrm{df}=3,66 ; \mathrm{p}=.103 ; \eta^{2}\right.$ partial $\left.=.089\right)$. Overall, the propensity to change LOA during a fault state was rather low. However, an examination of individual patterns revealed considerable differences between participants. About $30 \%$ of them made extensive use of LOA switching (10 or more times per testing session) while another $25 \%$ of participants changed LOA only once or not at all.

Manual control activity. As table 1 shows, there was a tendency for participants to use less manual control to stabilise the system across testing phases, resulting in a marginally significant main effect $\left(\mathrm{F}=2.61 ; \mathrm{df}=2.6,57.3 ; \mathrm{p}=.059 ; \eta^{2}\right.$ partial $\left.=.106\right)$. There was no effect 
of system reliability $\left(\mathrm{F}=.06 ; \mathrm{df}=1,22 ; \mathrm{p}=.81 ; \eta^{2}\right.$ partial $\left.=.003\right)$ and no interaction $(\mathrm{F}=.50 ; \mathrm{df}$ $\left.=2.6,57.3 ; \mathrm{p}=.66 ; \eta_{\text {partial }}^{2} .022\right)$.

\subsection{Complacency}

Completion of necessary system checks. This measure refers to the frequency with which critical information was sampled by participants (see table 1). The scores showed little change over time. This was confirmed by an analysis of variance, which showed neither a main effect of testing phase $\left(\mathrm{F}=1.80 ; \mathrm{df}=3,66 ; \mathrm{p}=.156 ; \eta^{2}\right.$ partial $\left.=.076\right)$ nor an interaction $(\mathrm{F}=1.57 ; \mathrm{df}$ $=3,66 ; p=.206, \eta^{2}$ partial $\left.=.066\right)$. However, there was an influence of reliability, with more information sampling taking place in the LoRel condition than in the HiRel condition $(\mathrm{F}=$ 7.55; $\mathrm{df}=1,22 ; \mathrm{p}=.012 ; \eta_{\text {partial }}^{2}=.256$ ).

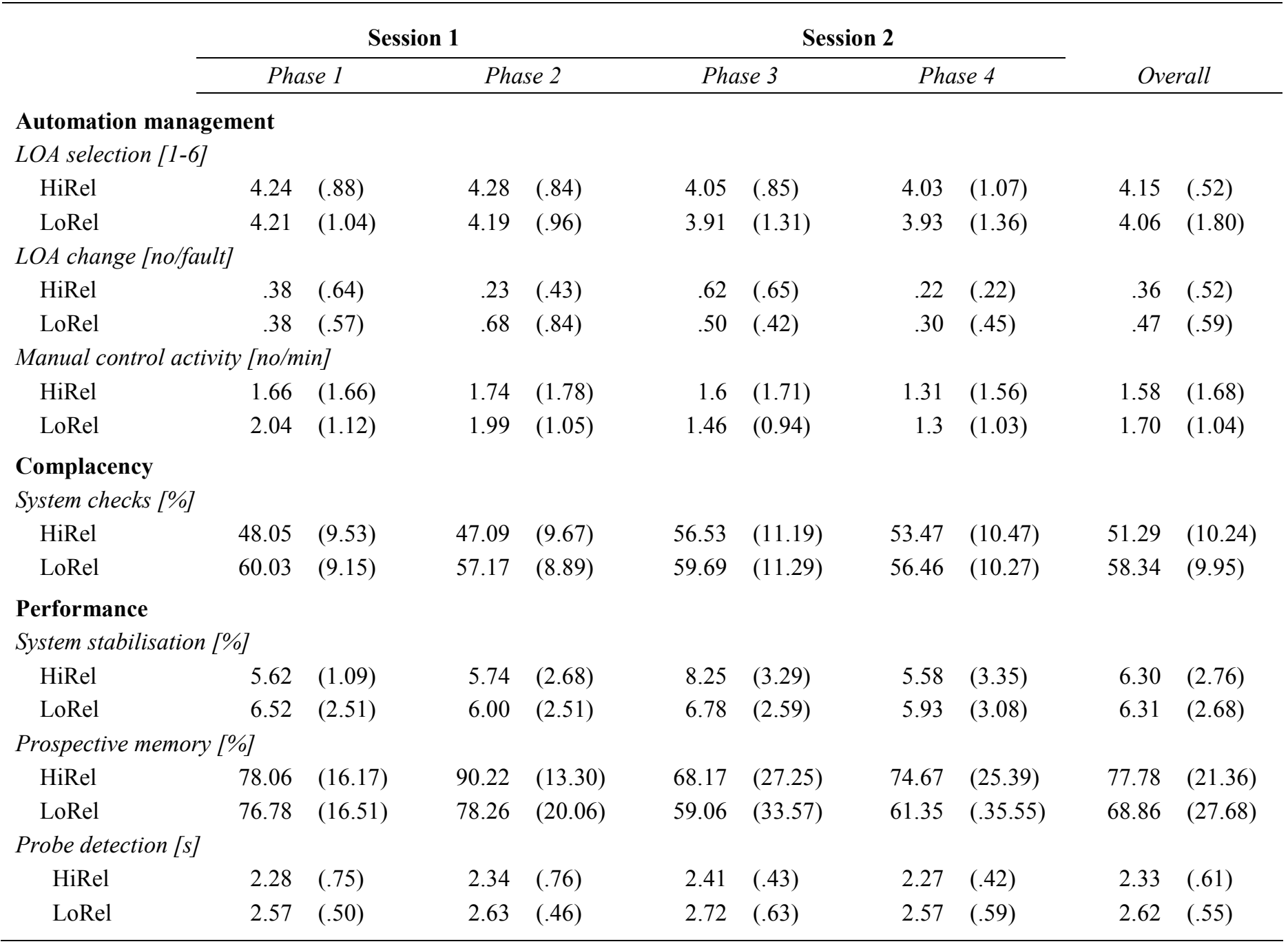

Table 1: Mean scores (and standard deviations) for automation management, complacency and performance as a function of testing phase and system reliability (HiRel: high reliability, LoRel: low reliability)

\subsection{Primary task performance}

Fault identification accuracy. The data for diagnostic accuracy are presented in figure 5. They show no effect of testing phase $\left(F=1.89 ; \mathrm{df}=2.5,55.7 ; \mathrm{p}=.141 ; \eta^{2}\right.$ partial $\left.=.079\right)$ but an 
interaction between testing phase and reliability $\left(\mathrm{F}=5.41 ; \mathrm{df}=2.5,55.7 ; \mathrm{p}=.004 ; \eta^{2}\right.$ partial $=$ .197). The graph shows differences in accuracy levels as a function of reliability for P1-3 while the difference had disappeared at P4, where reliability levels for both groups changed to $80 \%$. This result is confirmed by the planned comparison for reliability change $(\mathrm{F}=10.13$; $\mathrm{df}$ $=122 ; p=.004)$. The difference between reliability groups observed during the first three phases also resulted in a significant main effect $\left(F=19.8 ; \mathrm{df}=1,22 ; \mathrm{p}<.00 ; \eta_{\text {partial }}^{2}=.475\right)$.

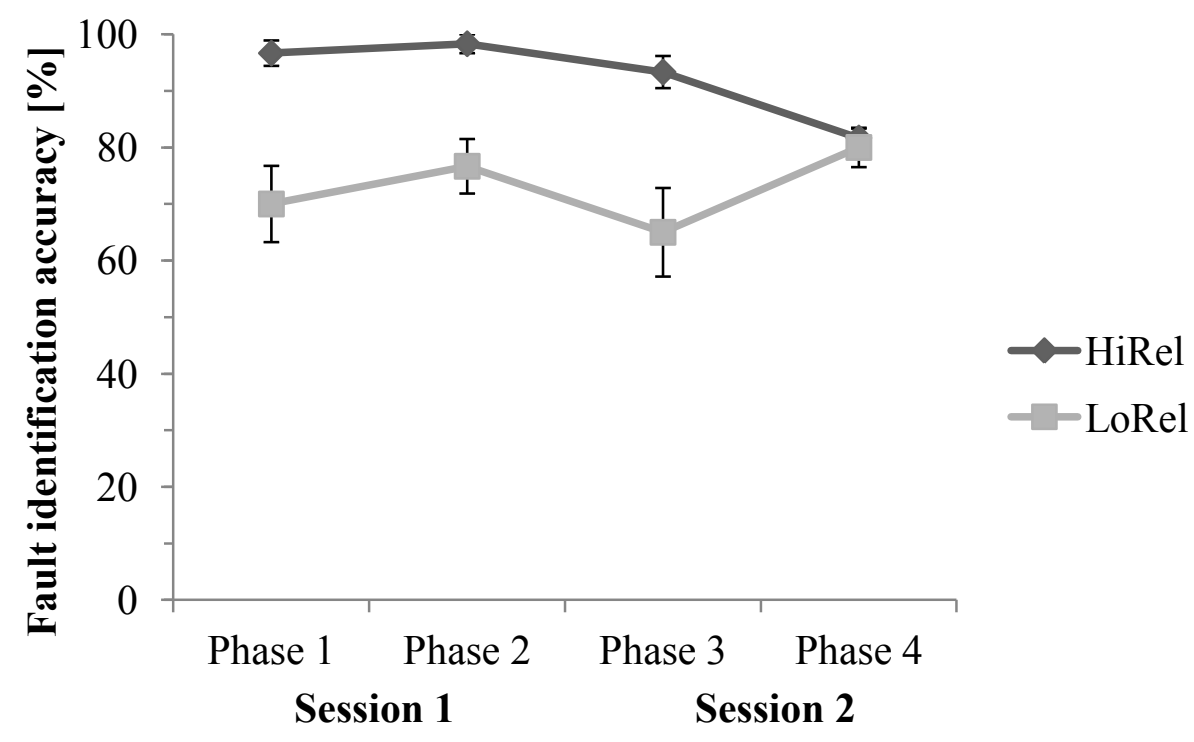

Figure 5: Mean scores for diagnostic accuracy (and standard errors) as a function of testing phase and reliability (HiRel: high reliability, LoRel: low reliability)

Fault identification time. Diagnostic speed as the second component of diagnostic performance showed the same pattern like the accuracy measure (figure 6). The data showed an effect of testing phase $\left(\mathrm{F}=4.91 ; \mathrm{df}=2.1,46.4 ; \mathrm{p}=.01 ; \eta^{2}\right.$ partial $\left.=.182\right)$, which was due to a slow-down in diagnostic speed after the retention interval (planned comparison: P1 vs P3: F = $5.90 ; \mathrm{df}=1,22 ; \mathrm{p}=.023)$. Furthermore, there was a significant interaction $(\mathrm{F}=10.2 ; \mathrm{df}=2.1$, $46.4 ; \mathrm{p}<.001 ; \eta^{2}$ partial $\left.=.317\right)$, which was due to the difference between HiRel and LoRel disappearing at $\mathrm{P} 4(\mathrm{P} 3-\mathrm{P} 4: \mathrm{F}=26.63 ; \mathrm{df}=1,22 ; \mathrm{p}<.001)$. The overall better diagnostic performance for the HiRel group from P1-P3 also resulted in a significant main effect of reliability $\left(\mathrm{F}=25.2 ; \mathrm{df}=1,22 ; \mathrm{p}<.001 ; \eta_{\text {partial }}^{2}=.534\right)$. 


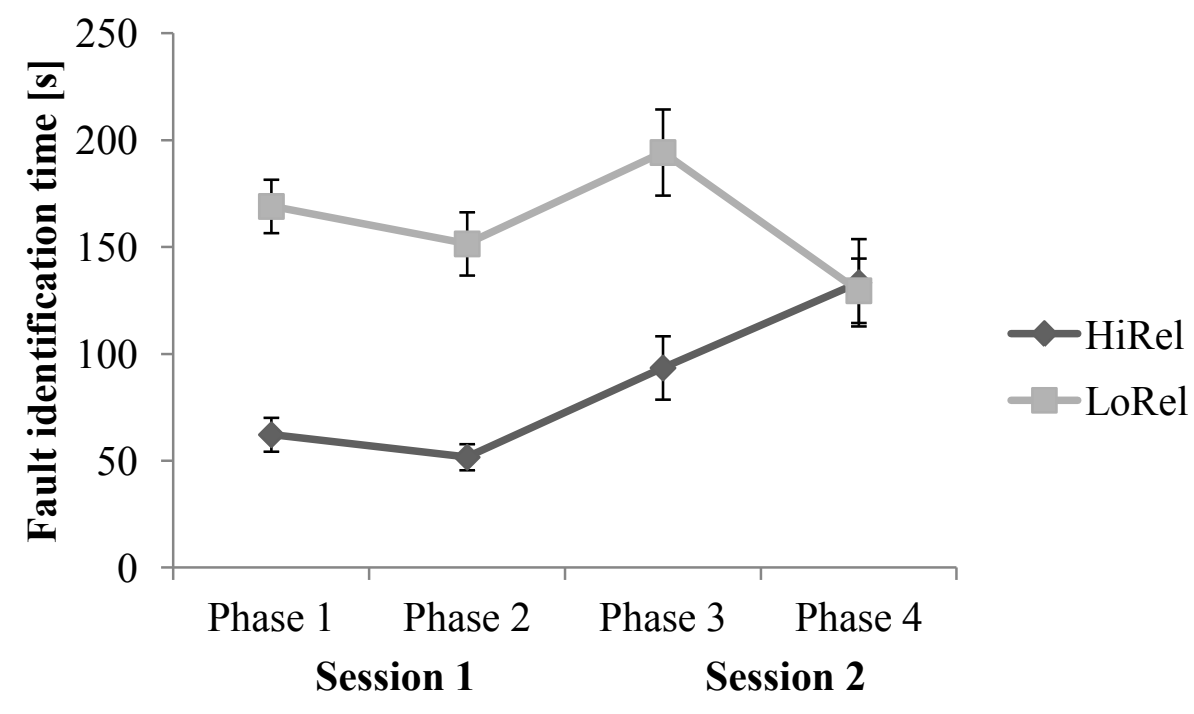

Figure 6: Mean scores for diagnostic speed (and standard errors) as a function of testing phase and reliability (HiRel: high reliability, LoRel: low reliability)

System stabilisation. The indicator of system stability showed a performance decrement after the retention interval at $\mathrm{P} 3$ but recovered again at $\mathrm{P} 4$ (see table 1). This temporary decrease in performance at $\mathrm{P} 3$ was statistically significant $\left(\mathrm{F}=3.36 ; \mathrm{df}=3,22 ; \mathrm{p}=.024 ; \eta_{\text {partial }}^{2}=.133\right)$ and confirmed by planned comparisons $(\mathrm{P} 1-\mathrm{P} 3: \mathrm{F}=4.9 ; \mathrm{df}=1,22 ; \mathrm{p}=.038, \mathrm{P} 3$ vs. $\mathrm{P} 4: \mathrm{F}=$ $4.96 ; \mathrm{df}=1,22 ; \mathrm{p}=.036)$. No interaction was observed $\left(\mathrm{F}=1.33 ; \mathrm{df}=1,66 ; \mathrm{p}=.273 ; \eta^{2}\right.$ partial $=.057)$ and there was no main effect of reliability $\left(\mathrm{F}=.01 ; \mathrm{df}=1,22 ; \mathrm{p}=.991 ; \eta^{2}\right.$ partial $=$ $.000)$.

\subsection{Secondary task performance}

Prospective memory. The accuracy of timing in making loggings of $\mathrm{N}_{2}$ tank levels showed changes over the different phases (see table 1$)$. There was a main effect of testing phase $(\mathrm{F}=$ $4.89 ; \mathrm{df}=1.6,36.2 ; \mathrm{p}=.018 ; \eta^{2}$ partial $\left.=.182\right)$. A planned comparison confirmed that performance was better at the first testing session than at the second $(\mathrm{P} 1-\mathrm{P} 3: \mathrm{F}=5.70 ; \mathrm{df}=1$ $22 ; \mathrm{p}=.026)$. Neither an effect of reliability $\left(\mathrm{F}=1.62 ; \mathrm{df}=1,22 ; \mathrm{p}=.216 ; \eta^{2}\right.$ partial $\left.=.069\right)$, nor an interaction $\left(\mathrm{F}=.41 ; \mathrm{df}=1.6,36.2 ; \mathrm{p}=.626 ; \eta_{\text {partial }}^{2}=.018\right)$ was observed.

Probe detection. As the data in table 1 show, alarm reaction time was not affected by testing phase $\left(\mathrm{F}=.35 ; \mathrm{df}=3,66 ; \mathrm{p}=.788 ; \eta^{2}\right.$ partial $\left.=.016\right)$. There was no interaction $(\mathrm{F}=.005 ; \mathrm{df}=3$, $66 ; p=.999 ; \eta_{2}^{2}$ partial $\left.=.000\right)$. However, an effect of reliability was recorded $(F=4.45 ; \mathrm{df}=1$, $22 ; \mathrm{p}=.046 ; \eta^{2}$ partial $\left.=.168\right)$, with faster reaction times being observed for the HiRel group.

\subsection{Correlational analysis of data}

Besides comparing experimental conditions by means of analysis of variance, a correlational analysis was carried out to gain a better understanding of the relationships between dependent variables. The results of the analysis revealed a number of significant associations, which are presented in table 2 . It emerged that higher workload was associated with higher trust ratings and poorer diagnostic performance (for speed and accuracy). Furthermore, there was a very strong relationship between speed and accuracy in diagnostic performance. The most interesting finding may be that more frequent LOA changes were associated with poorer diagnostic performance on both parameters. Furthermore, participants who changed LOA more frequently were also found to be more active in their manual control activities. Finally, it emerged that performance on the probe detection task was positive related to primary task 
performance (system stabilisation and fault identification) but no such relationship was observed between prospective memory performance and primary task performance.

\begin{tabular}{lllllllllll}
\hline & 1 & 2 & 3 & 4 & 5 & 6 & 7 & 8 & 9 & 10 \\
\hline 1. Trust [1-7] & 1 & & & & & & & & & \\
2. Self-confidence [1-10] & .20 & 1 & & & & & & & & \\
3. Perceived workload [1-20] & $-.53^{* *}$ & -.37 & 1 & & & & & & & \\
4. LOA selection [1-6] & -.09 & -.17 & -.22 & 1 & & & & & & \\
5. LOA change [no/session] & -.04 & -.26 & .22 & -.35 & 1 & & & & & \\
6. Manual control activity [no/min] & -.03 & .09 & .20 & $-.81^{* *}$ & .10 & 1 & & & & \\
7. System checks [\%] & -.06 & -.2 & .32 & -.29 & -.01 & .16 & 1 & & & \\
8. Fault identification accuracy [\%] & .16 & .16 & $-.52^{* *}$ & .28 & $-.48^{*}$ & -.13 & -0.22 & 1 & & \\
9. Fault identification time [s] & -.30 & -.12 & $.58^{* *}$ & -.32 & $.48^{*}$ & .21 & 0.32 & $-.86^{* *}$ & 1 & \\
1. System stabilisation [\%] & .01 & -.04 & .07 & -.16 & .20 & .31 & -0.23 & -.18 & .26 & 1 \\
11. Prospective memory [\%] & -.05 & .14 & -.10 & .24 & -.27 & -.15 & -0.16 & .39 & -.22 & -.10 \\
12. Probe detection [s] & -.39 & -.01 & .15 & 0 & $.47^{*}$ & -.07 & -0.2 & $-.47^{*}$ & $.57^{* *}$ & $.51^{*}$ \\
\hline
\end{tabular}

Table 2: Correlations between dependent variables $(\mathrm{N}=24):{ }^{*} \mathrm{p}<.05 ; * * \mathrm{p}<.01$

\section{Discussion}

This experiment aimed to examine how an extended lay-off period affected operator behaviour in a simulated work environment under wide-range and large-choice adaptable automation, comprising six levels. The results showed overall that subjective measures such as trust, self-confidence and workload were more sensitive to the impact of skill lay-off than objective measures of automation management behaviour (e.g. LOA changes, LOA choice, and complacency). Changes in system reliability had an impact on diagnostic performance but no other measures were affected.

When examining the effects of lay-off period, the first important finding was the decrease in self-confidence after the retention interval, though levels recovered in P4. Furthermore, levels of self-confidence were higher in the second phase of each testing session than in the first, suggesting that confidence levels were restored with continuous practice. This was similar to the pattern of findings of the reference study (Chavaillaz et al., 2016b), where participants also reported a loss of self-confidence after the retention interval. Interestingly, the decline in self-confidence was more pronounced for HiRel than LoRel, with differences between reliability groups having completely disappeared after the retention interval. The observations suggest that extended lay-off periods incur the risk of undermining operator self-confidence due to the lack of practice in managing the automatic system. Such a decrease in selfconfidence could also have implications on automation management behaviour in the form of higher automation levels being chosen (Lee \& Moray, 1994). However, in the present study no such increase was observed. Overall, self-confidence was not significantly associated with any other dependent variable, as the correlational analysis revealed.

The decrease in self-confidence was paralleled by an increase in trust ratings after the retention interval. Although operators did not use the system in the intervening period, their trust ratings increased and, even during the course of the second testing session, ratings did not return to the levels recorded in the first session. This pattern emerged for both low and high reliability. This increase in trust was not in line with our hypothesis, which was based on results from a previous study (Chavaillaz et al., 2016b). In the present study, it may not be 
surprising that the first trust rating after the lay-off period was not the same as the last one prior to it, considering the long time period participants were not exposed to the system. The decrease in self-confidence over the retention interval may have contributed to the increase in trust. This may have followed a pattern described by Moray et al. (2000), which suggests that participants trust the automation more than their own abilities when self-confidence declines. The increase in system trust may have also been influenced by the phenomenon that artefacts or events from the past are evaluated more positively as time goes by (e.g. Bahrick et al., 1996). While the findings from the present study are explicable, it remains unclear why the results were different from the reference study, which showed stable levels of trust between the two testing sessions. From the perspective of the operator, operational demands in the two studies were largely identical and differed only in the number of LOA being offered by AFIRA (which was larger by one in the present experiment). Since we do not believe that this factor accounts for the different results, further research may be needed to explain the differences.

While the lay-off period had effects on ratings of trust and self-confidence, no such effects were observed for objective measures of automation management behaviour. Operators did not change their LOA as a function of lay-off. This pattern was also observed in the reference study, which also simulated an extended period of skill lay-off (Chavaillaz et al., 2016b). It may depend on the nature of the demands made on the operator whether a change in LOA is initiated or not. Previous research provided evidence for such a change but also against it. When operators were faced with an increase or decrease change in reliability levels, no change in LOA was observed (Sauer, Chavaillaz \& Wastell, 2015). Conversely, when operators were faced with noise as a stressor, they did change LOA by giving more tasks to the automatic system (Sauer et al., 2011). Although one might have generally expected operators to make more use of higher LOA to allocate additional tasks to the automation (especially against the background of decreasing self-confidence), this did not occur. However, the low propensity of participants to change LOA found in the present study should not be used as an argument against the implementation of adaptable automation. The data showed that a considerable proportion of operators made use of the possibility of switching LOA (about $30 \%$ of them switched levels 10 times or more). Furthermore, it provides operators with the possibility of choosing their preferred LOA. This is an important aspect because there are considerable differences between operators with regard to the automation levels they predominantly use (e.g. Sauer, Chavaillaz \& Wastell, 2015). It also remarkable that the correlational analysis revealed that operator performance did not benefit from more frequent changes of LOA. If anything the opposite pattern was observed, with the two diagnostic performance indicators showing a negative association with frequent LOA changes.

Complacency as another relevant behavioural measure related to trust did not show any effects of skill lay-off, with the frequency of information sampling not being adjusted after the retention interval. A previous study (though not using adaptable automation) did not show any evidence for a reduction in information sampling either (which might be interpreted as complacency), with the sampling rate even increasing after the retention interval (Sauer, Hockey \& Wastell, 2000). This suggests that on the basis of the current empirical evidence, concerns about increasing operator complacency as a result of skill lay-off seem to be unjustified (despite increases in trust ratings). That is however not to say that complacency was not a problem, considering the information sampling rates reaching only about $55 \%$, which was considerably lower than in other studies with rates of more than $75 \%$ being recorded (e.g. Bahner et al., 2008). Overall, the findings for complacency as a behavioural 
measure were in line with the general picture that automation management behaviour was more stable over the lay-off period than subjective measures.

Whereas automation management behaviour did not change much as a function of skill layoff, effects were found for workload and some performance measures. After the retention interval, prospective memory performance as an objective indicator of workload decreased. A secondary task of this kind may represent a useful objective indicator of overall operator workload if it competes for the same resources as the primary task (Wickens \& Hollands, 2000). The decrease in prospective memory performance may indicate that operators found the overall task demands to be higher after the lay-off period, with fewer cognitive resources being available for the prospective memory task. This is corroborated by workload ratings, which also showed an increase after the lay-off period. In addition to the effects observed for objective and subjective measures of workload, primary task performance was also impaired by skill lay-off. The analysis revealed that diagnostic speed slowed down after the retention interval but diagnostic accuracy was maintained. This finding corresponds exactly to the results of an earlier study (Sauer, Hockey \& Wastell, 2000) suggesting that in the speedaccuracy trade-off priority was given to accuracy. However, these findings were partly in contrast to a recent study which found no changes in both measures of diagnostic performance after the lay-off period (Chavaillaz et al., in press-b). Whether a slow-down in diagnostic speed is observed or not may also depend on the extent to which operators make use of high LOA in a reliable system. This is because the contribution of the operator to joint humanmachine performance decreases with increasing automation levels.

Changing the level of reliability in $\mathrm{P} 4$ had an immediate and direct effect on diagnostic accuracy. The diagnostic accuracy scores (about 80\%) followed the actual reliability levels for both conditions (i.e. increase and decrease in reliability). The pattern for diagnostic speed was highly similar, also reflecting the changes in reliability. These results are in line with Wiegmann et al.'s (2001) observations. It may not be surprising that these two measures were directly affected by reliability since the main purpose of AFIRA was to support fault diagnosis. The results also suggest that operators experiencing a decrease in reliability were unable to compensate the lack of AFIRA support. This finding is in line with recent work using the same simulation environment (Wickens, Clegg, Vieane \& Sebok, 2015).

Furthermore, the pattern observed for fault management was not reflected in any of the other variables, be it subjective measures, automation management behaviour or performance. The adjustments for other variables may need more time to take place because operators need to experience a larger number of decisions of the automation (i.e. correct and false recommendations) to realise that reliability levels have changed. For example, Wiegmann et al.'s (2001) exposed participants to 100 trials after the change in reliability had occurred. Short-term adaptations of operators to changing reliability levels may therefore be difficult to observe. It is difficult to judge whether the results of the present study support the ' $70 \%$-rule' or provide contrary evidence (cf. Onnasch et al., 2014; Wickens \& Dixon, 2007). On the one hand, there was no improvement in diagnostic performance when reliability increased from $60 \%$ to $80 \%$ (i.e. crossing the $70 \%$ border). On the other hand, there was a difference in diagnostic performance between the $60 \%$ and $100 \%$ conditions. The question about the utility of a system with a lower reliability than $70 \%$ may also depend on the overall set of information it provides. In the present study, operators may have preferred relying on an unreliable support system rather than having no support at all. This is because they may have found it easier to check whether a recommendation of the automation was correct rather than having to identify the right fault out of a large list of possible faults. In more than half of the cases the recommendation of AFIRA was correct and only in a minority of cases (i.e. $20 \%$ or 
$40 \%$ ) they had to engage in the cognitively more demanding process of fault identification. Choosing the unreliable system may have therefore saved them from completing the full fault identification procedure every time. This suggests that there may be circumstances where even a not very reliable automatic system may be of some benefit to operators.

It may appear remarkable that trust ratings in the 100\%-reliability group were only between 4 and 5 on the 7-point scale. This may be related to the complexity of the simulation environment employed, which is characterised by a certain level of opaqueness. This makes it difficult for operators to understand all aspects of system behaviour to the full, which may result in reduced trust ratings. Furthermore, trust may build up slowly (Lee \& See, 2004) and may need more than some hours of experience with the system to achieve its maximum level. It may also appear remarkable that fault identification accuracy did not correspond to automation reliability. The reason is that operator interventions increased the $60 \%$-level of diagnostic accuracy (e.g. a false diagnosis of AFIRA was over-ruled by operator). Conversely, when the fault diagnosis of AFIRA was $100 \%$ correct, operators also sometimes overruled the decision of AFIRA resulting in a diagnostic error.

There are a number of implications that can be drawn from the present findings. First, in the present study no substantial performance decrements were observed after an extended period of skill lay-off. This suggests that adaptable automation is at least reasonable supportive even though we do not know whether alternative design options (e.g. static or adaptive automation) would have performed better or worse than adaptable automation. However, if it was critical to prevent even small performance decrements (which did occur in the present study) additional measures may need to be taken. For example, one may consider administering refresher training prior to operators beginning to work with the system after a lay-off period (see Kluge \& Frank, 2014). Second, the findings have indicated higher temporal stability for behavioural measures of automation management than for subjective operator state (e.g. trust, self-confidence and workload). The question is whether this rather high stability in automation management behaviour is always to the advantage of the operator. If the automation management behaviour is deemed to be sub-optimal, one may envisage several measures to ensure that the advantages of adaptable automation are used to the full. This may include measures that encourage operators to change LOA more often (e.g. training) or even force operators to change LOA (e.g. forced choice in automation design). Third, even though not all operators seemed to have taken advantage of the possibility of changing LOA, there is another argument in favour of offering adaptable automation. It would make it possible to cater for differences in operator preferences for automation levels.

\section{Acknowledgements}

The research was funded by a grant (No 100014_134566) from the Swiss National Science Foundation (SNSF). Their support is gratefully acknowledged. Thanks are also due to Dr Amos Brocco for modifying the software and to Julia Kratochwillova for her help with data collection. 


\section{References}

Annett, J., 1979. Memory for skill, in: Gruneberg, M.M., Morris, P.E. (Eds.), Applied problems in memory. Academic Press, London, pp. 215-247.

Arthur, W., JR., Day, E.A., Bennett, W., JR., McNelly, T.L., Jordan, J.A., 1997. Dyadic versus individual training protocols: Loss and reacquisition of a complex skill. J Appl Psychol 82 (5), 783-791. 10.1037/0021-9010.82.5.783.

Bahner, J.E., Hüper, A.-D., Manzey, D., 2008. Misuse of automated decision aids: Complacency, automation bias and the impact of training experience. Int J Hum-Comput Studies 66 (9), 688-699. 10.1016/j.ijhcs.2008.06.001.

Bahrick, H.P., Hall, L.K., Berger, S.A., 1996. Accuracy and distortion in memory for high school grades. Psychol Sci 7 (5), 265-271. 10.1111/j.1467-9280.1996.tb00372.x.

Casner, S.M., Geven, R.W., Recker, M.P., Schooler, J.W., 2014. The retention of manual flying skills in the automated cockpit. Hum Factors 56 (8), 1506-1516.

10.1177/0018720814535628.

Chavaillaz, A., Sauer, J., 2016. Operator adaptation to changes in system reliability under adaptable automation. Ergon.

Chavaillaz, A., Wastell, D., Sauer, J., 2016a. System reliability, performance and trust in adaptable automation. Appl Ergon 52, 333-342. 10.1016/j.apergo.2015.07.012.

Chavaillaz, A., Wastell, D., Sauer, J., 2016b. Effects of extended lay-off periods on performance and operator trust under adaptable automation. Appl Ergon 53, 241-251. 10.1016/j.apergo.2015.10.006.

Czaja, S.J., Sharit, J., 1993. Age differences in the performance of computer-based work. Psychol Aging 8 (1), 59-67. 10.1037/0882-7974.8.1.59.

De Visser, E., Parasuraman, R., 2011. Adaptive aiding of human-robot teaming: effects of imperfect automation on performance, trust, and workload. J Cogn Eng \& Dec Making 5, 209-131.

Driskell, J.E., Willis, R.P., Copper, C., 1992. Effect of overlearning on retention. J Appl Psychol 77 (5), 615-622. 10.1037/0021-9010.77.5.615.

Duncan, K.D., 1971. Long-term retention and transfer of an industrial search skill. Br J Psychol 62 (4), 439-448. 10.1111/j.2044-8295.1971.tb02057.x.

Dzindolet, M.T., Peterson, S.A., Pomranky, R.A., Pierce, L.G., Beck, H.P., 2003. The role of trust in automation reliance. Int J Hum-Comput Studies 58 (6), 697-718. 10.1016/S10715819(03)00038-7.

Endsley, M.R., 1995. Toward a theory of situation awareness in dynamic systems. Hum Factors 37 (1), 32-64. 10.1518/001872095779049543

Hagman, J.D., Rose, A.M., 1983. Retention of military tasks: A review. Hum Factors 25 (2), 199-213. 10.1177/001872088302500207 
Hancock, P.A., Vasmatzidis, I., 2009. Effects of heat stress on cognitive performance: The current state of knowledge. International Journal of Hyperthermia 19 (3), 355-372.

$10.1080 / 0265673021000054630$.

Hockey, G.R.J., 1997. Compensatory control in the regulation of human performance under stress and high workload: A cognitive-energetical framework. Biol Psychol 45 (1-3), 73-93. 10.1016/S0301-0511(96)05223-4.

Hockey, G.R.J., Wastell, D.G., Sauer, J., 1998. Effects of Sleep Deprivation and User Interface on Complex Performance: A Multilevel Analysis of Compensatory Control. Hum Factors 40 (2), 233-253. 10.1518/001872098779480479.

Hoff, K.A., Bashir, M., 2015. Trust in automation: Integrating empirical evidence on factors that influence trust. Hum Factors 57 (3), 407-434. 10.1177/0018720814547570.

Kluge, A., Frank, B., 2014. Counteracting skill decay: four refresher interventions and their effect on skill and knowledge retention in a simulated process control task. Ergon, 1-16. 10.1080/00140139.2013.869357.

Lee, J.D., Moray, N., 1994. Trust, self-confidence, and operators' adaptation to automation. Int J Hum-Comput Studies 40 (1), 153-184. 10.1006/ijhc.1994.1007.

Lee, J.D., See, K.A., 2004. Trust in Automation: Designing for Appropriate Reliance. Hum Factors 46 (1), 50-80. 10.1518/hfes.46.1.50_30392.

Lorenz, B., Di Nocera, F., Rottger, S., Parasuraman, R., 2002. Automated fault-management in a simulated spaceflight micro-world. Aviat Space Environ Med 73 (9), 886-897.

Manzey, D., Bleil, M., Bahner-Heyne, J.E., Klostermann, A., Onnasch, L., Reichenbach, J., Röttger, S., 2008. AutoCAMS 2.0 Manual. Berichte aus dem Fachgebiet Arbeits-, Ingenieurund Organisationspsychologie der TU Berlin. http://www.aio.tu-berlin.de/?id=30492. Accessed 29 June 2011.

Manzey, D., Reichenbach, J., Onnasch, L., 2012. Human performance consequences of automated decision aids: The impact of degree of automation and system experience. J Cogn Eng and Dec Making, 6, 57-87.

Matthews, G., Davies, D.R., Westerman, S.J., Stammers, R.B., 2000. Human performance: Cognition, stress and individual differences. Psychology Press, Hove.

Merrit, S.M., Heimbaugh, H., LaChapell, J., Lee, D., 2013. I trust it, but I don't know why: effects of implicit attitudes toward automation on trust in an automated system. Hum Factors $55,520-534$.

Moray, N., Inagaki, T., Itoh, M., 2000. Adaptive automation, trust, and self-confidence in fault management of time-critical tasks. J Exp Psychol: Appl 6 (1), 44-58. 10.1037/1076898X.6.1.44.

Onnasch, L., Wickens, C.D., Li, H., Manzey, D., 2014. Human performance consequences of stages and levels of automation: An integrated meta-analysis. Hum Factors 56 (3), 476-488. $10.1177 / 0018720813501549$. 
Parasuraman, R., Manzey, D., 2010. Complacency and bias in human use of automation: An attentional integration. Hum Factors 52 (3), 381-410. 10.1177/0018720810376055.

Parasuraman, R., Riley, V., 1997. Humans and automation: Use, misuse, disuse, abuse. Hum Factors 39 (2), 230-253. 10.1518/001872097778543886

Parasuraman, R., Sheridan, T., Wickens, C., 2000. A model for types and levels of human interaction with automation. IEEE Trans. Syst., Man, Cybern. A 30 (3), 286-297.

$10.1109 / 3468.844354$.

Philip, P., Taillard, J., Klein, E., Sagaspe, P., Charles, A., Davies, W., Guilleminault, C., Bioulac, B., 2003. Effect of fatigue on performance measured by a driving simulator in automobile drivers. J Psychosom Res 55 (3), 197-200. 10.1016/S0022-3999(02)00496-8.

Reichenbach, J., Onnasch, L., Manzey, D., 2011. Human performance consequences of automated decision aids in states of sleep loss. Hum Factors 53, 717-728.

Sauer, J., Chavaillaz, A., Wastell, D., 2015. Experience of automation failures in training: effects on trust, automation bias, complacency and performance. Ergon, 1-14.

10.1080/00140139.2015.1094577.

Sauer, J., Hockey, G.R.J., Wastell, D., 2000. Effects of training on short- and long-term skill retention in a complex multiple-task environment. Ergon 43 (12), 2043-2064.

10.1080/00140130010000893.

Sauer, J., Kao, C.-S., Wastell, D., Nickel, P., 2011. Explicit control of adaptive automation under different levels of environmental stress. Ergon 54 (8), 755-766.

$10.1080 / 00140139.2011 .592606$.

Sauer, J., Kao, C.-S., Wastell, D., 2012. A comparison of adaptive and adaptable automation under different levels of environmental stress. Ergon 55 (8), 840-853.

$10.1080 / 00140139.2012 .676673$.

Sheridan, T.B., Verplank, W.L., 1978. Human and computer control of undersea teleoperators. MIT Man-machine Systems Laboratory, Technical Report. Cambridge, MA.

Tucker, P., 2003. The impact of rest breaks upon accident risk, fatigue and performance: A review. Work \& Stress 17 (2), 123-137. 10.1080/0267837031000155949.

Vagia, M., Transeth, A.A., Fjerdingen, S.A., 2016. A literature review on the levels of automation during the years. What are the different taxonomies that have been proposed? Appl Ergon 53, 190-202.

Wickens, C.D., Clegg, B.A., Vieane, A.Z., Sebok, A.L., 2015. Complacency and automation bias in the use of imperfect automation. Hum Factors 57 (5), 728-739.

$10.1177 / 0018720815581940$.

Wickens, C.D., Dixon, S.R., 2007. The benefits of imperfect diagnostic automation: a synthesis of the literature. Theor Issues Ergon Sci 8 (3), 201-212.

$10.1080 / 14639220500370105$. 
Wickens, C.D., Hollands, J.G., 2000. Engineering psychology and human performance, Pearson Education/Prentice Hall, cop., Upper Saddle River NJ.

Wickens, C.D., Lee, J.D., Liu, Y., Gordon-Becker, S., 2004. Introduction to Human Factors Engineering, 2nd ed. Pearson Education/Prentice Hall, cop., Upper Saddle River NJ.

Wiczorek, R., Manzey, D., 2014. Supporting attention allocation in multitask environments: Effects of likelihood alarm systems on trust, behavior, and performance. Hum Factors 56 (7), 1209-1221. 10.1177/0018720814528534.

Wiegmann, D.A., Rich, A., Zhang, H., 2001. Automated diagnostic aids: The effects of aid reliability on users' trust and reliance. Theor Issues Ergon Sci 2 (4), 352-367.

$10.1080 / 14639220110110306$.

Wiener, E.L., 1988. Cockpit automation, in: Wiener, E.L., Nagel, D.C., Friedman, M.P., Carterette, E.C. (Eds.), Human Factors in Aviation. Elsevier Science, Burlington, pp. 433461. 